\title{
Comunicación

\section{Fealdad, alteridad y representación de la población latina en Estados Unidos en el discurso televisivo de $\boldsymbol{U} g l y$ Betty}

Ugliness, otherness and representation of the Latino population in the

United States in Ugly Betty's television discourse

\section{SANDRA LETICIA MURILLO SANDOVAL ${ }^{1} \mathrm{Y}$ \\ LUIS ESCALA RABADÁN2}

En este artículo analizamos la transformación de las representaciones de la población latina en Estados Unidos en la teleserie Ugly Betty, a través de una perspectiva sociológica y semiótica. Concluimos que dicha transformación constituye una ruptura importante en materia de la adaptación de géneros mediáticos y también una representación cultural más compleja de dicha población en la sociedad estadounidense.

PALABRAS CLAVE: Identidad y alteridad, representaciones mediáticas de los latinos en Estados Unidos, discurso televisivo, semiótica de la televisión, análisis de medios.
This work examines the transformations of the media constructions of the Latino population made in the television series Ugly Betty through a sociological and semiotic approach. Using sociological and semiotic approaches, it is concluded that such transformation constitutes an important difference in regard to the media genres involved, as well as a more complex cultural portrayal of such population in American society.

KEY WORDS: Identity and otherness, media representations of Latinos, television discourse, Semiotics of television, media analysis.

1 Universidad del Mar, México.

Correo electrónico: sandramsandoval@yahoo.com.mx

Ciudad Universitaria, C.P. 70989; Santa María Huatulco, Oaxaca, México.

2 El Colegio de la Frontera Norte, México.

Correo electrónico: luiser@colef.mx

Carretera Escénica Tijuana-Ensenada Km. 18.5, Col. San Antonio del Mar, 22709; Tijuana, Baja California, México. 


\section{INTRODUCCIÓN: LA CONSTRUCCIÓN MEDIÁTICA DE LA CULTURA}

La industria del entretenimiento se ha encargado de crear diversas formas de representación y fortalecerlas a través de los medios masivos. La televisión en específico nos permite observar diversos imaginarios representados en sus ofertas de consumo. Telenovelas, películas, talk shows, programas de concursos y seriales son productos en los que se construyen diversas narrativas muy cercanas a la realidad. Estas realidades son difundidas mediáticamente como discursos que generan procesos de producción de sentido y de construcción social de dicha realidad. Esto a su vez hace posible la formación de un imaginario, establecido a partir de sistemas de representación que se encuentran en toda sociedad o sistema cultural, y que permite conservar la memoria colectiva.

En este proceso, los sistemas de representación utilizados se basan en códigos reconocibles por la cultura contemporánea, entre los cuales están los formatos o géneros televisivos. Para Lacalle (2005), los formatos televisivos son un instrumento que nos permite visualizar procesos de producción de sentido, que a su vez revelan procesos industriales de producción cultural. La cuestión del formato se torna importante en particular al reflexionar sobre el papel del creador y del productor, el cual es decisivo y en gran medida está determinado por un asunto de mercadeo global sobre el entretenimiento televisivo (Orozco \& Vasallo, 2010). Para Mato (2005) la transnacionalización de algunas industrias de medios (como la televisiva) ha permitido la circulación de diversas culturas y la construcción de diversos marcos interpretativos sobre las mismas, mientras que Uribe (2008) señala el carácter transnacional del intercambio de bienes simbólicos y culturales que se dan a través de la televisión, y no solo como categoría de movilidad poblacional. Esta noción del proceso de intercambio muestra una de las formas en que nuestros imaginarios están siendo resignificados en pos de distintas lógicas que van desde lo económico y político hasta lo social y cultural.

De esta forma, el interés por examinar los nexos entre sistemas de representación y formatos televisivos se debe a que se busca tratar de explicar un doble proceso: a) el de la globalización de lo local, y b) el de la localización de lo global que se está dando en el nivel mundial y 
que se define con el término glocalización (Fernández, 2002). Al respecto, Orozco y Vasallo (2010) señalan que la tendencia de las ficciones es a la glocalización en la producción de guiones adquiridos en otros países. De esta manera, aunque existe la noción de la cultura desde lo local, el formato permite la globalización de diversos elementos culturales.

No obstante, para Lacalle (2008), el término globalización en el ámbito televisivo es un término comodín e híbrido, ya que su utilización se traduce en el ocultamiento de modos de producción multinacional. Al respecto, y a partir de su estudio sobre la representación televisiva de los inmigrantes, propone retomar los procesos de globalización como una red de interconexiones, donde los bordes de las geografías conceptuales serán más bien las nociones de identidad y alteridad, como elementos centrales que se observan en el análisis televisivo de lo latino e inmigrante.

Una adaptación singular que permite evidenciar tales procesos es la serie de televisión Ugly Betty. Esta producción televisiva estadounidense es una adaptación de la telenovela colombiana "Yo soy Betty la fea" (1999), escrita por Fernando Gaitán, 3 que se transmitió por la cadena $\mathrm{RCN}$ de Colombia y cuyo marcado éxito ${ }^{4}$ condujo a su posterior reproducción en varios países e idiomas. En el caso de la versión estadounidense, la adaptación de formato y de contenido fue posible al convertirla en una teleserie. Piñon (2011) explica que

3 Fernando Gaitán encabezó el equipo de escritores, en el que también participaron Elsa Cortéz y Liliana Hernández.

4 Ugly Betty tuvo un notable impacto desde su aparición en Estados Unidos en 2006, cuando la cadena ABC decidió incluirlo en su programación abierta en horario prime time (jueves a las 8:00 pm). El primer capítulo de esta serie se estrenó el 28 de septiembre de 2006 y fue visto por 16 millones de espectadores en ese país. Tal característica la convirtió en la emisión más vista de la cadena en los últimos 10 años en su franja horaria. Además, fue la primera serie que obtuvo la renovación por parte de ABC. En su primera temporada obtuvo 11 nominaciones a los premios Emmy (que se otorgan a lo mejor de la televisión), donde América Ferrera ganó el premio de mejor actriz y Salma Hayek a la mejor producción. 
la adaptación final que tuvo el formato obedeció a una negociación institucional, basada en el creciente valor económico de los productos híbridos, las culturas híbridas y las identidades latinas en el contexto de un mercado multicultural.

Ugly Betty nos narra la historia de Beatriz Suárez, una joven méxico-estadounidense hija de inmigrantes "ilegales"5 mexicanos, quien vive con su padre (su madre murió), su hermana Hilda y su sobrino Justin, en una casa que se encuentra ubicada en un barrio de inmigrantes en el área de Queens. Betty habla inglés y estudió una carrera profesional, lo que le permite eventualmente conseguir un trabajo en la compañía editorial de la acaudalada familia Meade, en la revista de modas llamada Mode.

El punto de partida de la trama es la difícil interacción entre una mujer latina, ${ }^{6}$ fea, pobre, de ascendencia mexicana y mal vestida en un mundo en el que impera la elegancia mainstream y lo convencionalmente bello. No obstante, el desarrollo de la serie plantea una reformulación del concepto de fealdad que se construye más como una oposición cultural que como una oposición estética, en contraste con lo que ocurría en las adaptaciones anteriores de la telenovela. Esta característica en su construcción establece una relación entre el concepto de fealdad y la identidad a través del uso del personaje de Betty Suárez, que en la serie termina representando a la población latina y migrante

5 Este es el término utilizado en la serie para referirse a ellos, y no como indocumentados.

6 Según George Yúdice (2009) cinco años después de que se eliminaron las cuotas migratorias (por la Ley Hart-Celler en 1965) en el censo de 1970 se empezó a usar el término Hispanics para los descendientes de latinoamericanos. Este autor cuenta que en el censo de 1940 ya había tentativas de llamar a estos descendientes Spanish surnamed, tras varios intentos se definió a los hispanos por su etnicidad y su no pertenencia a las categorías raciales históricas de blancos, negros y nativos estadounidenses. Estas características étnicas permitían agrupar a los mexicanos, puertorriqueños, cubanos, u otros, ya sea como Spanish/Hispanic/Latino. Por tanto, como dice Yúdice, a los latinos se les considera una etnia que puede pertenecer a cualquier raza. 
en Estados Unidos. Al mismo tiempo, tal relación sirve como vehículo para presentar la reconfiguración de las relaciones entre dicha identidad y la sociedad mainstream estadounidense (representada por su entorno laboral y sus personajes). Tales vínculos están estructurados en relaciones binarias de oposición simbólica (belleza/fealdad, mujer latina/ mundo anglosajón, etc.).

Así mismo, nuestro análisis de esta teleserie se inserta en el creciente interés académico por la representación pública y comercial de distintos sectores de la población en lugares como Estados Unidos, en particular la representación pública de la identidad latina en dicho país como parte de la relación de una sociedad dominante con sus "otros". Tal como lo señala Dávila (2001), este creciente interés se deriva del dejar atrás la diferenciación estricta entre la esfera racional de la política y la esfera comercial del entretenimiento, lo que ha permitido examinar la manera en que se construyen las identidades públicas y un sentido cultural de ciudadanía, y con ello analizar las formas en que se producen y negocian diversos sentidos de pertenencia, en contextos de creciente transnacionalismo y desplazamiento. Esto es, en buena medida, el contenido de Ugly Betty, así como el recorrido de Betty Suárez en esta narración televisiva.

En las secciones subsiguientes se presentarán dos ejemplos sobre relaciones binarias de oposición simbólica y su transformación durante la narración televisiva de esta serie desde una perspectiva semiótica. Al final se reflexionará sobre las implicaciones en términos de las representaciones culturales de la alteridad en el medio televisivo. Tal explicación proviene de un análisis más extenso sobre las estrategias narrativas usadas para construir la relación entre la fealdad simbolizada en el personaje de Betty, su condición latina y los sistemas de valores asociados a la noción del "otro". La metodología utilizada para observar, delimitar las unidades de análisis, codificar y hacer la interpretación correspondiente se deriva del modelo propuesto por Greimas y Courtés (2006) denominado "recorrido generativo", el cual hemos retomado del texto de Courtés (1997). Tal modelo permite explicar el modo como se genera y se articula el sentido en un texto narrativo. El análisis permitió identificar las unidades mínimas de significado que se construyen en el texto televisivo a partir de su estructura narrativa. 
Dicha estructura en esta teleserie contaba hasta el momento en que fue observada con tres temporadas (65 capítulos). La temporada observada fue la primera debido a que las bases de la narración, tanto en el nivel de contenido como estructural, se construyeron desde la primera temporada. ${ }^{7} \mathrm{Al}$ tener un formato serial, se prevé que la estructura formal se repetirá de la misma manera en las subsecuentes temporadas, aunque es importante observar las posibles variantes, ya que cada temporada cuenta con su propia historia.

El criterio para seleccionar unidades de análisis se dio a partir de lo que se ha conceptualizado como relato y macrohistoria, los cuales nos permiten entender la lógica narrativa que se desprende de las acciones de Betty, el personaje principal de la teleserie. Los relatos nos permiten identificar las historias que inician y terminan en una sola emisión, es decir, en un capítulo de 40 minutos. En contraste, las macrohistorias se construyen en espacios más amplios de narración. Así, una historia que pudo iniciar en algún capítulo puede tener continuidad en los capítulos subsiguientes $\mathrm{y}$, por tanto, tener una conclusión seis o siete capítulos después del inicio. Esto implica que las macrohistorias deberán ser actualizadas por un televidente que va reconociendo la continuidad durante la temporada completa. Para ello, como ya lo señalamos, se tomaron los 23 capítulos (relatos) de la primera temporada, en los que se observaron las estructuras semionarrativas 8 en la construcción del actante Betty sobre las modalidades aléticas (del ser) y deónticas (éticas) asociadas a su posición como sujeto externo a la cultura dominante. Al respecto, la primera temporada contaba con 23 capítulos (relatos) y 22 macrohistorias.

Para los fines de este artículo se recupera en primer lugar una de las macrohistorias de la primera temporada que está compuesta por los capítulos (relatos) 7, 8, 9, 10, 11 y 12 de la serie, que nos muestra la for-

7 Un análisis más extenso sobre la primera temporada completa de esta teleserie está desarrollado en Murillo (2010).

8 "Las estructuras narrativas o, mejor, estructuras semionarrativas, deben comprenderse, entonces, en el sentido de estructuras semióticas profundas (que presiden la generación del sentido e incluyen las formas generales de la organización del discurso)" (Greimas \& Courtés, 2006, p. 162). 
ma en que se genera una oposición semántica de tipo espacial sobre lo latino y lo anglosajón; en segundo lugar el capítulo cinco, el cual constituye un relato que muestra el sistema de valores atribuido en la representación televisiva a la oposición cultural del "nosotros" y el "ellos".

\section{LA CONSTRUCCIÓN SOCIAL DEL “OTRO”}

El estudio semiótico del discurso televisivo (entendido como un sistema de significación) nos permite distinguir aquellas construcciones que son simbólicamente relevantes. Sabemos que en los procesos de comunicación se construyen saberes sociales, ya que según MartínBarbero (2002), muchas de las fronteras entre los diversos espacios que se mantenían en la sociedad se han disuelto y las formas de transmisión y circulación de información han cambiado en gran medida gracias a la televisión. Este medio, de acuerdo con Martín-Barbero, permitió la visualización de escenarios, se convirtió en un espacio abierto que hizo posible la deslocalización de saberes y desplazó las fronteras entre razón e imaginación, saber e información, trabajo y juego. En ese sentido, es pertinente retomar el señalamiento del propio Martín-Barbero, puesto que nos explica que la televisión ha transformado nuestras formas de consumir sus productos, convirtiendo la experiencia de ver la televisión en un proceso de fragmentación, de reconocimiento de palimpsestos, de hipertextos y de intertextos.

Específicamente, esta construcción de saberes al interior de la televisión depende de la forma en que se decida construirla para el consumo. En el caso de Ugly Betty, esta serie fue adaptada para su consumo en Estados Unidos, lo que explica su construcción como teleserie, es decir, fragmentada y serial. La historia central es acompañada de un sinfín de pequeñas historias que son presentadas en un periodo de tiempo específico y que constituyen el discurso en el que dicho personaje está inmerso. Así, Betty es construida al interior de este género como una chica fea (al igual que la telenovela en los muchos países donde se reprodujo), pero que además es pobre, ordinaria, de ascendencia mexicana, y que sin embargo muestra una forma de leer la fealdad al interior de una sociedad que es muy parecida a la forma en que ese concepto es entendido globalmente. La fealdad, por tanto, se ha convertido en 
una característica global, es decir, no hay sociedad que no comprenda el signo que se construye para dar identidad a este personaje como una chica fea físicamente, pero bella en su interior.

De esta forma, el uso de lo bello y lo feo que se había dado en las versiones anteriores de la telenovela se modifica en esta serie televisiva con el fin de proveernos de una nueva forma de ver el mundo. La fealdad de Betty, al ser positiva, la construye como un personaje femenino que en lugar de ser fea, es no bella. Esta oposición, que parte de una lógica gramatical, se pone en escena al mostrarnos a la protagonista como alguien que simplemente es no bella y que va dejando fuera paulatinamente las connotaciones de lo convencionalmente feo. Como resultado, tanto los otros personajes de su entorno social y laboral, así como el receptor de la teleserie deberán reformular sus saberes sociales para aprender a ver a Betty como no bella y no como una persona fea, ya que en la trama de la teleserie, a diferencia de la telenovela, Betty Suárez no llega a tener una metamorfosis física. ${ }^{9}$ No obstante, desde este punto de vista, lo que se plantea es más bien una transformación de la mirada externa (tanto de los otros personajes como de los televidentes), una mirada que transforme la visión que los otros tienen sobre el sujeto feo.

La adaptación de una historia exitosa, en materia de géneros televisivos, nos permite observar una nueva construcción discursiva, que al ser traducida a un país determinado es permeada por el contexto en el que está inmersa. Así, la versión estadounidense de Ugly Betty construye un mundo posible, reconocible y cognoscible, un universo semiótico donde el personaje de Betty Suárez se ve representado, reconstruido y fortalecido por sus características étnicas, de clase social y de género.

En ese sentido, dicha adaptación televisiva es también una aproximación a la construcción identitaria, que es la que experimenta Betty Suárez a través de la interacción con aquellos "otros" personajes con los que convive al interior de la serie, en sus espacios correspondientes,

9 Según el escritor Fernando Gaitán, quien participó en la elaboración de la serie en Estados Unidos, ella no podrá tener dicha metamorfosis porque sus características étnicas se lo impedirían. 
como lo son las revistas Mode y MYW (Modern Young Woman) en Manhattan, que constituyen el entorno laboral de Betty, y la casa de Betty en Queens, como el lugar donde se desarrolla su vida familiar. Tales espacios se convierten en signos referenciales de este proceso identitario que permiten plantear las diferencias étnicas, de clase y de género dentro de la trama, pero en particular las relaciones de dominación/ subordinación entre los grupos, culturas e identidades seleccionadas para formar parte de la historia narrada.

Por su parte, los roles sociales que cumplen los personajes al interior de la historia nos develan signos identitarios que nos muestran la existencia significativa de distintas sociedades (la anglosajona, la latina, la afroamericana) y su cultura en el contexto estadounidense contemporáneo. Esto permite apreciar la existencia de determinados grupos étnicos que al interactuar en un mismo espacio generan significados correspondientes a las diferencias, contrastes y fronteras entre dichas comunidades étnicas dentro de la teleserie.

En nuestro análisis, la puesta en escena del fenómeno étnico y sus distintos niveles se corrobora mediante los actores sociales (personajes), espacios e imágenes construidas y visualizadas a través del discurso de Ugly Betty. A su vez, la puesta en escena de este discurso permite apreciar las representaciones que se elaboran sobre la población latina en Estados Unidos (y ocasionalmente sobre la población inmigrante mexicana), y con ello su relación con los "otros", es decir, su alteridad.

La alteridad construida a través de la ficción ha sido examinada con detalle por Lacalle (2008), quien retoma las aportaciones de Eric Landowski (1993) sobre la oposición nosotros/ellos. En esta dualidad, "la afirmación del sujeto en cuanto persona se produce precisamente en el descubrimiento del otro" (p. 98). Por ello, el concepto de alteridad de Lacalle nos permite observar cómo el descubrimiento del otro (de la diferencia) legitima la asociación del yo con sus semejantes. De esta forma, desde nuestro objeto de estudio, se puede apreciar cómo la narración de procesos de interacción en espacios de solidaridad o identidad social permite a un grupo diferenciarse de otros. Con ello, estos espacios hacen posible a su vez la construcción discursiva tanto de identidades como de su alteridad. 


\section{LA DIFERENCIACIÓN A TRAVÉS DEL ESPACIO REPRESENTADO}

Nuestra perspectiva sobre la condición de mujer latina de la protagonista, hija de inmigrantes mexicanos en Estados Unidos, recae en una serie de interrelaciones que mantiene con otros sujetos que se afirman como diferentes. Tales diferencias tienen que ver con prácticas culturales, idioma y desde luego con los espacios en que se desenvuelven. En ese sentido, este uso del espacio en la teleserie nos permite apreciar la noción de fronteras en materia de diferencias socioculturales que se ponen en escena y que son verificables a través de los espacios narrados donde se lleva a cabo la interacción.

$\mathrm{Al}$ respecto, Betty posee una noción de comunidad que tiene que ver con sus orígenes (México y los mexicanos), pero al mismo tiempo con una comunidad estadounidense y sus habitantes. Esta pertenencia se basa, en principio, en un sentido de identidad étnica, es decir, el:

Conjunto de repertorios culturales interiorizados (representaciones, valores, símbolos) a través de los cuales los actores sociales (individuos o colectivos) demarcan simbólicamente sus fronteras y se distinguen de los demás actores en una situación determinada, todo ello en contextos históricamente específicos y socialmente estructurados (Giménez, 2000, p.28).

De tal manera, uno de los problemas que surgen en la trama es el tema de la adscripción y la pertenencia. A lo largo de la temporada cuentan cómo el padre de Betty ${ }^{10}$ se ve en problemas cuando necesita unas medicinas y le confiesa a Betty su condición de indocumentado. Pocos días después le avisan que su padre será deportado. Ante ello, Betty y su padre realizan un viaje a Guadalajara, México, con dos propósitos: ayudar a su padre a tramitar la visa y que así pueda regresar a Estados Unidos, y reencontrarse con el lugar en donde su madre vivió, conocer a su familia (de la cual tiene conocimiento por las charlas de su padre) y tratar de "saber quién es realmente". De esta forma, Betty

10 Esta historia constituye una de las macrohistorias más extensas, está compuesta por los capítulos $1,2,4,5,6,7,10,13,14,17,19,20$ y 21 de la primera temporada. 
se adscribe a una doble comunidad: por un lado a lo mexicano (por su padre, por su familia, por su forma de vida en el espacio familiar) y, por otro lado, a lo estadounidense, el lugar donde nació, ha crecido y ha aprendido la lengua, y que se trata de una comunidad de la que quiere formar parte plenamente.

Al respecto, Lacalle (2008) profundiza en las proposiciones de Landowski (1993) respecto del espacio social y de la representación de sectores socialmente excluidos (como los inmigrantes) en el discurso televisivo, y afirma que se puede determinar la lógica de las relaciones que condicionan la constitución del "nosotros" a la producción paralela de un "ellos". Para esto, Landowski homologa la identidad psicológica y filosófica a la lingüística, considerando que es desde el ego/ nosotros donde se articula la estructura de las relaciones sociales y que, a diferencia de este, el él/otro se puede definir a partir de su exclusión del espacio social o de su confinamiento. Para Lacalle (2008), esto es determinante en lo que se refiere a la representación mediática de la exclusión social, y lo retoma para explicar que:

En las sociedades democráticas (sustentadas sobre la premisa teórica de la igualdad), las figuras del mundo que encarnan los dos polos extremos de la diversidad social son el extranjero y el marginal. El primero procede del exterior del espacio social, mientras que el marginal ha sido expulsado de dicho espacio social ... La ubicación del extranjero y del marginal en relación al cuerpo social de referencia (leyes, tradiciones, valores, etc.) determina importantes diferencias entre ambos (p. 101).

Así, una de las constantes a lo largo de la serie es la reconfiguración de las fronteras culturales entre los personajes, es decir, la línea que se establece entre la forma en que Betty se autoadscribe a un grupo determinado con una idea compartida y la forma en que es percibida por sus compañeros de trabajo (heteroadscripción). Al interactuar con algunos de sus compañeros, lo que podemos observar es cómo se construyen esas diferencias objetivas entre los diversos grupos y cómo se mantienen las fronteras culturales a partir de las prácticas que se muestran inequiparables. 
Un claro ejemplo de cómo se construyen dichas fronteras se aprecia en la macrohistoria (que mencionamos al inicio del artículo, compuesta por los capítulos 7, 8, 9, 10, 11 y 12)11 en la que Betty debe decidir, en torno a una serie de valores, el lugar al que quiere pertenecer, entre la revista Mode (que preside Daniel Meade) y la revista $M Y W$ (que preside Sofía Reyes). Para ello, de acuerdo a la trama, Betty se ve en la disyuntiva de decidir entre Sofía Reyes, una exitosa ejecutiva también de origen latino (interpretada por Salma Hayek) y Daniel Meade, lo que genera dos recorridos narrativos distintos. El objeto del deseo de Betty al inicio de la narración parece ser obtener un puesto más alto, ser redactora y no solo asistente, lo cual puede conseguir trabajando en $M Y W$ con Sofía Reyes. Durante la narración ese objeto cambia puesto que lo que ella tenía pensado sobre el cambio de trabajo y el ascenso social que obtendría se ve truncado por una cuestión ética. De tal suerte que se construyen dos lógicas posibles: a) Betty debe ser leal a Daniel y regresar a trabajar con él después de que Sofía lo traiciona; b) Betty debe no/ser leal a Daniel para seguir trabajando con Sofía y así tener ascensos.

La lógica se manifiesta en dos espacios distintos a los que se les otorgan determinados valores que durante la narración serán transformados: entre el espacio que "parece ser como ella" (espacio de "lo latino") y el que ella decide "es como ella" (espacio de multiculturalidad) se vislumbra la mentira y la verdad. Estas oposiciones generan dentro de una lógica gramatical la aparición de un valor modal denominado alético (sobre la verdad): en Mode son y parecen, por lo tanto esa relación construye verdad; en $M Y W$ parecen pero no son, así construye mentira. Betty es de Mode pero no parece, tal relación construye secreto.

La construcción permite que la protagonista sea vista a través de valores positivos. Su relación con el espacio se establece entre estar en la verdad y no estar en la mentira. La verdad para Betty es Mode, por eso ella afirma encajar en ese espacio. Por el contrario, $M Y W$ está en la mentira, espacio donde Betty no se reconoce y por tanto no se siente parte de él.

11 Los nombres de los capítulos son: Trust lust and must, After hours, Four thanksgiving and a funeral, Lose the boss, Fake plastic snow, Sophia's choice. 
Estas diferencias objetivas, tal como menciona Barth (1979), se vuelven realmente importantes en la medida en que los receptores las consideren significativas. Estos últimos son los que activan el mecanismo de comprensión e interpretación de esta parte de la historia, y de la demarcación y las diferencias entre cada uno de los personajes que son representados en la narración televisiva. De acuerdo a la premisa inicial de dicha narración, esta es la razón por la que Betty jamás podrá sentirse incluida en la sociedad anglosajona: Betty podrá aprender a vestir diferente, podrá compartir prácticas cotidianas (tomar café, ir de compras, etc.), podrá aprender a comer cosas light y cambiar su lugar de residencia, pero jamás podrá cambiar su etnicidad y su condición social, a partir de lo cual la señalan en su entorno laboral y la hacen cargar con el estereotipo del latino en Estados Unidos. No obstante, los giros que presenta la trama se centran precisamente en la transformación tanto de esta premisa como de las percepciones en sí de los personajes.

La narración de esta serie se desarrolla dentro de un universo anglosajón que intenta poner a la vista un espacio, representado por la revista Mode en Manhattan, construido sobre de la dicotomía de inclusión/ exclusión de diversas comunidades étnicas, en donde cada personaje funge como un signo que devela una identidad sociocultural y por tanto diferencia. De esta forma, podríamos considerar que a través de estos marcos, la teleserie pone en marcha la idea de una posible sociedad multicultural, que toma en cuenta la diversidad y la reúne en un espacio determinado en donde en principio puede haber cabida para todos. Por lo tanto, es también claro que hace falta más que solo adscribirse para estar "dentro".

Lo anterior significa que en la narración no es suficiente que todas estas comunidades estén juntas en un mismo espacio, puesto que la misma Betty experimenta el rechazo de la comunidad donde se inserta desde el primer momento. Sin embargo, lo que veremos sucesivamente en la narración es cómo la protagonista hará valer sus principios, generando una creciente aceptación en su lugar de trabajo, donde sus compañeros siempre la verán como "el otro" y a pesar de ello aprenderán a convivir con ella en ese mismo espacio.

Esto es presentado de manera más ilustrativa en la macrohistoria mencionado anteriormente, en el que Betty comenta que Mode y la gente 
a su interior son más parecidos a ella, al compararlo con otros espacios con los que parecería tener más afinidad. Esto es un giro importante en la trama, ya que se da tras rechazar la invitación que le hace Sofía Reyes. Betty decide dejar de lado la posibilidad de trabajar en un medio con otros empleados latinos y con una jefa latina, frente a lo cual señala: "de hecho creo que encajo mejor allá (en Mode) que aquí (en $M Y W$ )". En términos de la trama televisiva, esto significa que Betty se inserta mejor en un proyecto de sociedad multicultural imaginado y representado por Mode, a pesar de las diferencias externas y las fronteras culturales existentes.

De esta forma, la trama de la teleserie presenta así un giro fundamental, al proceder de un entorno en el que prevalece la exclusión (con base en lo que es considerado convencionalmente bello), para dar paso paulatinamente a un espacio donde la diferencia encuentra acomodo. Ciertamente, aunque estas comunidades se encuentren compartiendo el mismo espacio, existen fronteras culturales, es decir, fronteras imaginarias que sirven de periferia y que permiten la semantización y la definición de umbrales mediante los cuales se construye esa diferencia. No obstante, la diferencia permite también la construcción de determinadas identidades que se reflejan en este proyecto multicultural imaginado, este mundo en donde el multiculturalismo es posible. Según Valenzuela (2003) el multiculturalismo nos remite a:

Los procesos de estructuración de las identidades colectivas, especialmente en lo que se refiere a la conformación de umbrales de adscripción y diferencia, y busca un replanteamiento profundo de la condición de las minorías en la sociedad y en las culturas nacionales (pp. 15-16).

Así, la construcción discursiva que se presenta en esta teleserie nos revela una sociedad que si bien no es real, sí refleja un posible proyecto de inclusión de diversas comunidades étnicas cuyos miembros aspiran a ser respetados como individuos en la narración. A su vez, a través de sus interacciones, Betty nos muestra cómo este espacio de multiculturalidad aún crea fronteras entre los que se consideran "equivalentes" o "iguales" en contraposición a los "otros", los de fuera.

Este acercamiento nos ha permitido entender las construcciones que son parte de la reformulación que se hizo de la telenovela "Yo soy Betty 
la fea" al serial Ugly Betty. Al observarlas, podemos explicar cómo se discursiviza la inclusión de categorías sociales como las de exclusión/ inclusión, belleza/fealdad, extranjero/inmigrante o población latina, entre otras. En este sentido, una de las preguntas que orientó la adaptación que llevó a cabo la teleserie fue: ¿cómo se logra aparentar que se es semejante al "otro"? Betty, que sirve como un signo que connota y denota significados, se procede a partir de la reconstrucción social de sus diferencias en lo individual y lo colectivo. Hemos señalado que sus diferencias radican en su concepción social como miembro de la población latina en Estados Unidos y como mujer estéticamente fea. En la última parte del texto, examinaremos la estructura cultural a la que responde el diseño de esta serie televisiva.

\section{EL ESPACIO CULTURAL COMO ESPACIO DE ALTERIDAD}

Desde la perspectiva de la semiótica conocida como lotmaniana, la cultura es el espacio donde se comparten procesos de semiosis, en el que se crean textos y estos circulan, generando procesos de comunicación, información y memoria entre los individuos. Retomamos esta perspectiva porque, de acuerdo con Lotman (1998), cada cultura genera un tipo de descripción sobre sí misma, una especie de metalenguaje. Esto plantea la existencia de una tipología sobre la cultura que involucra dos perspectivas: la "cultura propia" que se considera como única, a la cual se le opone la "no cultura" de las otras colectividades. Esta conceptualización implica la contraposición de dos sistemas culturales, en donde la cultura "propia" se vislumbra como de "carácter organizado" y se contrapone a la de "carácter no organizado". Esta perspectiva nos permite observar la manera en que, desde el punto de vista de cierta cultura, se construyen oposiciones fundamentales. La "no cultura" aparece así como una cultura no significante, a la que se le otorga un significado diferente.

Una de las características principales de la teoría lotmaniana es la existencia de la frontera entre un sistema cultural y otro. Cada sistema cultural, o semiosfera, construye al interior relaciones de centro y periferia. En el centro, la semiosis es menos evidente ya que los signos que definen a la cultura son menos reconocibles, la relación que se establece entre ellos no es cuestionada por los individuos de la cultura puesto 
que se da por hecho. En la periferia el proceso es inverso, la lectura de signos se ve comprometida por el lugar del observador.

Por ejemplo, esto es lo que ocurre cuando un extranjero visita otro país: los procesos de lectura del extranjero y el nativo son distintos ya que que uno se encuentra en el centro de la semiosfera y el otro en la periferia. Esto se hace evidente cuando comprendemos que la cultura no existe hasta que llega alguien "de fuera" y muestra la diferencia de lectura entre los signos. Nadie sabe cómo funciona su sistema cultural hasta que sale del mismo, es decir, hasta que se aleja del centro de la semiosfera y se sitúa en la periferia, lo que le permite al sujeto convertirse en un traductor cultural. Así mismo, esto también permite la creación de oposiciones entre sistemas culturales, entre la noción de cultura organizada y no organizada, entre la cultura propia y la no cultura.

Por ello, el espacio del texto (incluyendo el texto televisivo) permite al investigador describir la organización interna del modelo de mundo que fue construido, no solo espacial, sino religioso, social y ético, entre otros. Por tanto, el texto no es solo un sistema de clasificación y de representación del mundo sino que incluye un sistema de valorización. Esto significa que en el lenguaje de las relaciones espaciales, los conceptos serán expresados a través de un medio de orientación del espacio que serán evidentes si el tipo de división reproduce el esquema de la construcción del mundo: lo de arriba/lo de abajo, izquierdo/derecho, de este lado de la frontera/de aquel lado de la frontera, incluyente/excluyente. Tales construcciones permiten un proceso de textualización de los valores que los individuos exponen en los textos.

Debido a esto, para Lotman (1998) la perspectiva de la frontera cultural permite explicar la división del espacio de la cultura. La frontera básica, que es construida y representada a través de los textos que crean los sujetos de la cultura, divide el espacio en dos partes, el interno y el externo. La más simple interpretación semántica de tal oposición será la noción del nosotros $\leftrightarrow$ ellos. Tal oposición puede interpretarse de dos formas: nosotros (interno) $\leftrightarrow$ ellos (externo); nosotros (externo) $\leftrightarrow$ ellos (interno). Lo relevante de esta propuesta radica en el hecho de que cualquier oposición plantea de un lado el rasgo de la organización y del otro lado su ausencia para cada sistema cultural, o mejor dicho, para el sistema cultural que se esté observando. 
Para el caso de esta teleserie, un ejemplo de tales oposiciones se observa en el capítulo (relato) cinco. ${ }^{12}$ En ese capítulo, el sobrino de Betty, Justin, engaña a su madre (Hilda) y a Betty diciéndoles que tenía que realizar una tarea para la escuela sobre Mode, situación por la cual Betty le había permitido asistir a su trabajo. Cuando Hilda se da cuenta de que Justin no está haciendo esta tarea, sino que se trata de un pretexto para faltar a clases, se lo comenta a Betty, quien regaña a Justin y se genera el siguiente diálogo:

Betty: ¿Así que estás faltando a la escuela?

Justin: No importa, solo falté a Educación Física y a Arte, ¡y en Arte nos la pasamos dibujando frutas!

Betty: Eso no es lo importante, Justin, este lugar (Mode) que te parece tan encantador, no es lo que parece, ahí la gente engaña, oculta la verdad y ese tipo de cosas, eso no es bueno para un niño. Algún día quizá llegues a trabajar en un lugar como ese, pero no llegarás muy lejos en la vida si mientes. Así no somos nosotros. 13

La oposición básica que se muestra en este capítulo nos permite observar la visión desde la cual se habla, hay un "nosotros" (externo) y un "ellos" (interno) que constituyen un sistema de diferenciaciones, principalmente de tipo moral en este caso. Existe un "nosotros" externo (enunciado por Betty) que implica o señala la no pertenencia, la traducción cultural que se lleva a cabo del "ellos". El "ellos" está representado por Mode, por sus compañeros de trabajo que indiscutiblemente son estadounidenses. Pero el "nosotros" de Betty va más allá de su familia, ella se refiere al lugar del que provienen, a la sociedad de la que ella forma parte y de la que se desprende para incluirse en el espacio de los anglosajones. Cuando ella dice "Así no somos nosotros", se está alejando, está construyendo diferencias entre su sistema cultural y el sistema cultural en el que se ve inmersa. En consecuencia, el carácter organizado es tratado como el ingreso en un mundo cerrado, que según lo expuesto por Lotman, expresa un "Nosotros tenemos N",

12 El nombre del capítulo es: Fey's sleigh ride.

13 Traducción realizada a partir de la enunciación del capítulo. 
donde "N" puede variar según sea el rasgo que se aprecie, en este caso un valor moral.

Esta idea de que toda cultura crea su sistema de organización interna y su propio sistema de desorganización externa, está sujeta a la idea de la invención del "otro", del bárbaro, aquel individuo que no habla mi lenguaje, o mejor dicho, aquel que no tiene un lenguaje común a mi cultura. Sin embargo, Gómez (2008/2009) nos recuerda que más que hablar del concepto trillado del "otro" como categoría estereotipada, como construcción social de la realidad que se ha estudiado en las perspectivas postcolonialistas y culturales, se debe hablar de la noción del otro como una instancia discursiva y por tanto cultural. Es por eso que no buscamos estereotipar la oposición dada por un "nosotros" y un "ellos", a pesar de que es evidente la manera en que se discursiviza la oposición.

Desde esta perspectiva, el sujeto externo genera narrativas ya sea en la lengua natural del sistema dominante o en cualquier otro código propio traducible, y de esta manera entra a formar parte del logos del sistema cultural y de sus propios procesos de semiosis, aunque sea de manera marginal. Tal enfoque es observable, en buena medida, a través de personajes como Betty y lo que representan, en su condición de mujer latina descendiente de migrantes mexicanos, puesto que generan sus discursos desde el sistema cultural dominante, por eso es que la posición discursiva del "nosotros" es desde lo externo. Sin embargo, las oposiciones discursivas se crean y se mantienen por este proceso de traducción centro/periferia.

Es en este punto que la categoría de traductor cultural, o "narrador fronterizo" (Gómez, 2008/2009), desempeña un papel fundamental en la medida en que se convierte en narrador o constructor de los discursos. Llevar a cabo esa traducción significa que semiotizan lo externo y lo adaptan a lo interno. De manera específica, un texto televisivo como Ugly Betty nos permite identificar la manera en que los individuos de cierta cultura, al estar situados en la periferia, pueden observar el sistema cultural estadounidense y el latino/mexicano, y buscan traducir elementos para construir narrativas adaptadas al medio. Así, estos sujetos fronterizos o traductores convierten la no-información en información para los miembros de esa cultura. Esto es posible, según Gómez 
(2008/2009), por la existencia de lo que se podría considerar el narrador fronterizo, es decir:

El elemento en posición hegemónica que entra en contacto con el mundo más allá de sus fronteras (geográficas, políticas y culturales) e intenta integrarlo y transmitirlo a los "suyos", casi siempre valiéndose de imágenes preconstruidas. El elemento foráneo que normalmente recibe la agresión (en distintos grados) que supone, bien la conversión a una esfera cultural que le es ajena (el "otro" conquistado, el extranjero por criterios territoriales, religiosos, culturales y lingüísticos), bien el rechazo o la no admisión dentro de una misma esfera cultural (p. 12).

El concepto de traductor cultural o narrador fronterizo nos permite entender no solamente la manera en que en la serie se crea un discurso con oposiciones ligadas a lo cultural, sino que también nos permite observar la lógica de la adaptación de un género como las telenovelas, que provienen de una tradición cultural específicamente latinoamericana, a otro género televisivo distinto. La adaptación funciona así como una traducción en la que los narradores fronterizos o traductores culturales juegan un doble papel: otorgan una característica clave al personaje principal, a través de un sujeto que intenta integrar la información a los "suyos" valiéndose del estereotipo latino; pero también los traductores fungen como "sujetos foráneos" en la realización misma de la historia (hay que recordar que Fernando Gaitán, el autor colombiano de la telenovela, participó en la elaboración de la teleserie, y que la productora era Salma Hayek, actriz mexicana en Estados Unidos), lo que supone la conversión a una esfera cultural como la de Estados Unidos, de la que conocen la reducida admisión hacia los latinos en ese medio.

\section{CONCLUSIONES}

El análisis de la serie Ugly Betty es un ejemplo de cómo la televisión constituye un gran lente que visualiza las formas en que la cultura funciona a través de la representación de sus imaginarios. Al respecto, la perspectiva semiótica y sociológica adoptada en este texto nos permite apreciar la construcción de significados que adquieren los personajes de 
esta serie, las categorías que les son atribuidas, y la manera en que se presenta y desarrolla la representación de los sujetos sociales.

Nuestro punto de partida ha sido el análisis de la presencia de un personaje como Betty Suárez, que representa un sujeto social al interior de la serie Ugly Betty que se desenvuelve en un espacio en el que los demás personajes lo perciben como alguien extraño, extranjero, distinto: no solo como un individuo feo, según las normas estéticas convencionales, sino como alguien diferente, no perteneciente a ese espacio de la cultura. Es en este punto en el que la trama televisiva se aparta notablemente de la historia original, al incorporar el tema de la exclusión/ inclusión social y su resolución mediante la propuesta de la multiculturalidad en Estados Unidos. Por tanto, Betty luchará para ser aceptada en ese espacio social en el que predominan los anglosajones, y a la vez buscará conservar sus valores familiares y culturales, lo que le permitirá trascender su apariencia física y su condición social. Por tal motivo, su transformación, más que física, es una transformación sociocultural, de integración a un espacio que inicialmente la rechaza no solamente por su apariencia, sino por su no pertenencia, para dar paso a un espacio en el que la diferencia puede tener cabida.

En suma, la transformación de Betty en esta serie, como lo señalamos en su momento, si bien se trata de una propuesta televisiva de proyecto social imaginario, constituye a su vez la adopción de un mayor grado de complejidad en la trama de la serie respecto de la versión original, pero sobre todo es una propuesta alternativa en lo que se refiere a la representación cultural de los sujetos sociales, los diversos mecanismos de exclusión y las posibilidades de inclusión, particularmente de la población latina y mexicana en Estados Unidos.

\section{Bibliografía}

Barth, F. (1979). Los grupos étnicos y sus fronteras. La organización social de las fronteras culturales. México: FCE.

Bigwood, J. \& Hayek, S., Horta, S., Silverman, B., Hayman, J. \& Parriott, J. D. (Productores ejecutivos). (2006). Ugly Betty [serie de televisión]. La primera temporada completa. EE.UU.: BuenaVista Home Entertainment, Inc/ABC Studios. 
Courtés, J. (1997). Análisis semiótico del discurso del enunciado a la enunciación. Madrid, España: Gredos.

Dávila, A. (2001). Latinos, Inc. The marketing and making of a people. Berkeley, CA, EE.UU.: University of California Press.

Fernández, P. S. (2002). La glocalización de la comunicación. Ámbitos: Revista Internacional de Comunicación. Recuperado el 20 de enero de 2011 de http://www.ull.es/publicaciones/latina/ambitos/7-8/ arti08.htm

Giménez, G. (2000, octubre). Culturas e identidades. Revista de Sociología, 24 (66), 77-99.

Gómez, P. L. (2008/2009). El espacio fronterizo. Entretextos. Revista electrónica semanal de estudios semióticos de la cultura, 11, 12, 13. Recuperado el 19 de abril de 2010 de http:/www.ugr.es/ mcaceres/ entretextos/entre11-12/pdf/laura.pdf

Greimas, A. J. \& Courtés, J. (2006). Semiótica. Diccionario razonado de la teoría del lenguaje. Madrid, España: Gredos.

Lacalle, Ch. (2005). Los formatos de la televisión. Barcelona, España: Gedisa.

Lacalle, Ch. (2008). El discurso televisivo sobre la inmigración. Ficción y construcción de identidad. Barcelona, España: Omega.

Landowski, E. (1993). Ellos y nosotros: notas para una aproximación semiótica a algunas figuras de la alteridad social. Revista de Occidente, $140,98-118$.

Lotman, I. (1998). La semiosfera II. Semiótica de la cultura, del texto, de la conducta y del espacio. Madrid, España: Cátedra.

Martín-Barbero, J. (2002). Jóvenes: comunicación e identidad. Pensar Iberoamérica. Revista Cultura. Recuperado el 10 de septiembre de 2009 de http://www.oei.es/pensariberoamerica/ric00a03.htm

Mato, D. (2005). The transnationalization of the telenovela industry, territorial references, and the production of markets and representations of transnational identities. Television and New Media. Recuperado el 16 de abril de 2009 de http://tvn.sagepub.com/cgi/content/ abstract/6/4/423

Murillo, S. (2010). Belleza, fealdad y otredad: la construcción televisiva de la población migrante mexicana en Estados Unidos a través de Ugly Betty. Tesis de Maestría no publicada, El Colegio 
de la Frontera Norte/Universidad Autónoma de Baja California, Tijuana, México.

Orozco, G. \& Vassallo de Lopes, M. (2010). Observación de la ficción televisiva en ocho países iberoamericanos. Comunicación y Sociedad, 13, 13-42.

Piñon, J. (2011, diciembre). Ugly Betty and the emergence of the latina/o producers as cultural translators. Communication Theory, 4 (21), 392-412.

Uribe, A. (2008, diciembre). Transnacionalismo mediático. La ficción televisiva como vínculo entre el origen y el destino. Trabajo presentado en III Coloquio Internacional sobre Migración y Desarrollo, Costa Rica.

Valenzuela J. M. (2003). Introducción. Crónica y estudios culturales en México. Teorías de la cultura. México: FCE.

Yúdice, G. (2009). Culturas emergentes en el mundo hispano de Estados Unidos. Observatorio: Cultura y Comunicación. Recuperado el 16 de abril de 2010 de http://www.falternativas.org/en/layout/set/ print/occ-fa/documents/culturas-emergentes-en-el-mundo-hispanode-estados-unidos

Fecha de recepción: 27/07/11. Aceptación: 26/04/12. 